BLS 35, No 1 2009. DOI: http://dx.doi.org/10.3765/bls.v35i1.3626

(published by the Berkeley Linguistics Society and the Linguistic Society of America)

\title{
Negation and the Untransitive Category in Karitiâna
}

\author{
CALEB EVERETT \\ University of Miami
}

\section{Introduction}

This work describes aspects of negation in Karitiâna ( $\mathrm{K}$ henceforth), a Tupí language spoken by approximately 260 people in the state of Rondônia, Brazil. K is one of two languages in the Arikém branch of Tupí, the other of which is now extinct (cf. Rodrigues 1999). The language, which is transitivizing (in the sense of Nichols et al. 2004), split-ergative, and head-marking (cf. Storto 1999, Everett 2006), employs several different morphemes for clausal and constituent negation. Below I provide an overview of clausal negation, focusing on the manner in which clauses with semantically transitive verbs are negated. In doing so, I will demonstrate the manner in which negated transitive predicates resemble affirmative intransitive predicates. Furthermore, it will be seen that clauses with these two sorts of predicates resemble clauses with negated imperative predicates, as well as those with negated interrogative predicates. Morphologically, there is a certain degree of isomorphism among these clause types, as well as a shared semantic feature. The semantic similarity of such clause types is reflected in the structure of other languages, in which imperatives, negatives, and interrogatives are subsumed under an irrealis mood (cf. e.g. Payne 1997). However, in this case the data cannot be described so simply, since realis-like intransitive clauses also fall into the relevant semantic category in K. I conclude by providing a synchronically-oriented account of the category, which I refer to as the untransitive.

\section{Relevant Background on K Morphosyntax}

Before delving into the clausal negation data, some general comments on $\mathrm{K}$ grammar are in order. With respect to grammatical relations, the language is splitergative. As Everett (2006, chapter 15) notes, morphological phenomena in the language are generally oriented according to an ergative-absolutive distinction, while syntactic phenomena are generally oriented according to a nominativeaccusative distinction. For instance, verbs tend to agree with the absolutive referent in a clause, as evidenced by pronominal affixation, irregular number agreement, as well as aspect agreement. In the latter case, the aspect marking of a particular verb often denotes a particular body posture as well, and this body 


\section{Caleb Everett}

posture describes the position of the absolutive referent. The nominativeaccusative alignment, meanwhile, surfaces in syntactic phenomena such as controller-pivot relationships, quantifier float, and word order in simple declarative clauses. The association of morphology and ergativity, and conversely between syntax and nominativity, is of course not unique to K. Furthermore, it has been previously noted that in many languages with overwhelmingly ergative morphology, the distinction between intransitive and transitive predicates is significant to the language's morphosyntax (though Dixon 1994:216 suggests this correlation is often overstated). Perhaps not surprisingly, then, the distinction between semantically intransitive and semantically transitive predicates surfaces in $\mathrm{K}$ in a number of ways. As we will see, the morphological reification of this distinction is quite relevant to the patterns of clausal negation in the language.

All verbs in $\mathrm{K}$ are classified as either semantically intransitive or semantically transitive. More accurately, we might state that all verbs are either classified as semantically monovalent, in which case their argument structure requires one and only one semantic macrorole (i.e. "actor" or "undergoer" in the sense of Van Valin 2005), or semantically multivalent, in which case their argument structure requires at least two, but possibly more, semantic macroroles. Since the vast majority of semantically multivalent verbs are semantically transitive, requiring only two arguments, I will refer to the distinction as one between semantically intransitive and semantically transitive verbs. This distinction surfaces in a variety of ways in $\mathrm{K}$ morphology. For example, semantically intransitve predicates receive different inflections, vis-à-vis semantically transitive ones, in interrogative, imperative, and negated clauses. For a survey of the relevant distinctions, I refer the reader to Everett (2006). Some of these distinctions were also described in Landin (1984) and Storto (1999). Interestingly, the distinction between semantically intransitive and semantically transitive verbs also surfaces in some declarative clauses. This fact, which will prove quite relevant for the rest of this discussion, was not described until Everett (2006), for reasons that will become clear shortly.

There are several basic declarative clause construction types in $\mathrm{K}$, most of which fall outside our present purview. Crucially, one of these construction types only occurs with semantically intransitive predicates, which are inflected in such cases with an $i$ - prefix denoting their intransitive status. Semantically transitive predicates cannot be inflected with this prefix in declarative clauses, and must be inflected instead with a na(ka)- or ta(ka)- prefix. ${ }^{1}$ In (1) I provide a sample list of short declarative clauses and their translations, in order to illustrate the morphological differences between semantically intransitive and transitive declarative clauses in K. All verbs are inflected for the basic nonfuture tense $(-t /-\varnothing)$ and occur with the first person singular pronoun $\tilde{\mathrm{t}} n$.

\footnotetext{
${ }^{1}$ For a detailed discussion of this prefix set, I refer the reader to Everett (2006:409-423). Note that this prefix set is also attached to semantically intransitive verbs. However only semantically intransitive verbs can occur with $i$ - prefixation instead in declarative clauses.
} 


\section{(1) Examples of semantic valency distinction in $\mathbf{K}$.}

\begin{tabular}{|c|c|}
\hline Intransitive Verb & Translation \\
\hline t̃n i-taktãyã-t & 'I swam’ \\
\hline inn i-sombak & 'I looked' \\
\hline ๓̃n i-hã:nã-t & 'I breathed' \\
\hline ĩn i-sẽna-t & 'I crouched' \\
\hline in i-mbik & 'I sat' \\
\hline in $\mathrm{i}-$ pikina-t & 'I ran’' \\
\hline in i-tarika-t & 'I walked' \\
\hline in i-tat & 'I went' \\
\hline in i-kisep & 'I jumped' \\
\hline Transitive Verb & Translation \\
\hline in naka-mĩ:-t & 'I hit X' \\
\hline ĩn naka-ki:p & 'I cut X' \\
\hline in naka-?i-t & 'I ate $\mathrm{X}$ ' \\
\hline in naka-m?a-t & 'I made X' \\
\hline ĩn naka-mhip & 'I cooked X' \\
\hline 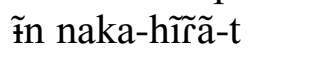 & 'I smelled X' \\
\hline ĩn naka-hi:t & 'I gave X' \\
\hline in naka-pi:t & 'I took X' \\
\hline in naka-pidn & 'I kicked X' \\
\hline
\end{tabular}

The examples in (1) suggest that the semantic basis offered above for the distinction between intransitive and transitive verbs, is generally accurate. Clearly the clauses in the left-hand column of (1) denote events that generally occur with one participant/referent, while those in the right-hand column denote events that most typically occur with two participants/referents. While other semantic factors often correlate with this distinction, this is the only factor that needs to be appealed to in describing this basic distinction in $\mathrm{K}$ grammar. Other aspects of scalar transitivity (cf. Hopper and Thompson 1980), e.g. telicity, kinesis, volitionality, and agency are of course relevant to the distinction, but primarily as they relate to the one-participant vs. two-participant distinction. For instance, two participant actions tend to involve volitional agents and telic actions, but there are many clause-level exceptions in which a transitive verb describes e.g. an atelic nonpunctual event.

It is worth noting that there are many more semantically intransitive verbs in the language, both in terms of number of lexemes and in terms of tokens in discourse. This is true of language more generally, however, as authors such as Thompson and Hopper (2001) and Everett (2009) have noted. 


\section{Caleb Everett}

\section{Specific Morphosyntactic Data}

\subsection{Negation of Semantically Intransitive Verbs}

Landin (1984) pointed out a very interesting aspect of the negation of intransitive predicates. Specifically, he noted that such clauses are in many cases less-marked than their affirmative counterparts. For instance, consider the two clauses in (2) and (3), the second of which is an example of a negated intransitive predicate. ${ }^{2}$

$\begin{array}{lll}\dot{\mathrm{i}} & \text { ta-oti-j } & \text { in } \\ \text { 1S } & \text { SAP-bathe-FUT } & \text { 1S.ABS }\end{array}$

(3)

í-otì-̃̂n

1S-bathe-1S.ABS

'I will not bathe.'

(Landin 1984:237)

Note that the negated intransitive in (3) is less marked, morphologically, than the affirmative intransitive in (2). It is also unmarked prosodically, since the intonation associated with declarative clauses (falling on the final syllable) is maintained in negative clauses in $\mathrm{K}$.

This less marked status of (3) is not characteristic of all negated intransitives, however. For instance, in (4) we see that monosyllabic intransitive verbs in negative clauses are prefixed with $\boldsymbol{r} \dot{t}$-, and we also observe that consonant-final intransitive verbs in such clauses are suffixed with $-\dot{\boldsymbol{t}}$, when negated.

$$
\begin{array}{ll}
\text { ì-ri-tat-i } & \text { in } \\
\text { 1S-NEG-go-NEG } & \text { 1S.ABS } \\
\text { 'I will not go.' } &
\end{array}
$$

Furthermore, I should note that examples such as (3) and (4), while grammatical, are unusual in that negated intransitive verbs are almost always followed by the free morpheme padni. When asked how to back-translate the Portuguese version of (3), for instance, all $\mathrm{K}$ respondents tested employed padni. It is unclear whether this morpheme was as prevalent at the time Landin collected his data, in the 1970s.

\subsection{Negation of Semantically Transitive Verbs}

In this paper we are concerned primarily with the negation of semantically transitive predicates, since in such cases similarities between negated transitives and declarative semantically intransitive verbs surface, as in examples (5)-(13), in

\footnotetext{
${ }^{2}$ The gloss SAP in example (2) refers to speech act participant. As noted in Everett, verbs inflected with $t a(k a)$ - occur with a speech-act-participant as the absolutive referent. Those inflected with $n a(\mathrm{ka})$ - occur with a non-speech-act participant as the absolutive referent.
} 
which the verbs once again occur with the first person singular pronoun and nonfuture tense affixation.
(5) in i-hã:nã-t
'I breathed'
(6) ก̃ i-tat-ø
'I went'
(7) in i-irit- $\varnothing$
'I came'
(8) $\quad$ in i-sena-t
'I crouched'

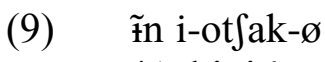
(10) Ĩn i-pajop-ø
*'I bit it'
'I didn't bite it'
* 'I scraped it'
'I didn't scrape it'
*'I opened it'
'I didn't open it'
(11) n i-kindop- $\varnothing$
(12) ก̃n i-soki-t
*'I broke it'
'I didn't break it'

As we see in these examples, declarative clauses with the basic intransitive inflection, such as (5)-(8), may be isomorphic with clauses with negated transitive verbs, such as (9)-(12). In examples (9)-(12), there is no overt second participant. However, there is an implicit second participant that, if not recoverable from context, may be understood in these cases to represent an inanimate $3^{\text {rd }}$ person referent. (See also the examples in (1) above.)

The semantic motivation for this structural isomorphism will be discussed below. First, however, it is worth noting that examples similar to those in (9)-(12) have been accounted for in a different manner in K, both in Landin (1984) and Storto (1999). It appears, however, that in crucial ways the significance of such examples has been missed.

Landin (1984:238) posits a rule of direct object epenthesis, in which the more patientive argument of a transitive clause is represented pre-verbally via $i$, the third person pronoun in $\mathrm{K}$, which is unmarked for gender or animacy. Landin provides the following example ${ }^{3}$ :
ĩn i paka-ø ĩn pikip
I it clean I clothes
'I will not clean the clothes.'

There are two reasons such an account does not quite fit the $\mathrm{K}$ data. Before detailing these, it is worth mentioning that $\mathrm{K}$ does have a $3^{\text {rd }}$ person pronoun $i$.

\footnotetext{
${ }^{3}$ For the examples taken from Landin (1984) and Storto (1999), which are transcribed orthographically in the original works, I maintain my phonetically-oriented transcriptions for the sake of transparency. The glosses are taken directly from the relevant works.
} 


\section{Caleb Everett}

This pronoun could be used as in the following two examples, which can be contrasted with (6) and (10), respectively: ${ }^{4}$
(14) i i-tat-ø
3 INT-go-NFUT
'S/he/it went.'

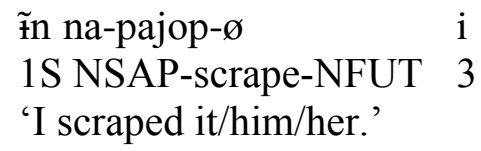

in na-pajop-ø

1S NSAP-scrape-NFUT 3

'I scraped it/him/her.'

This free pronoun $i$ differs synchronically from the $i$ - prefixation evident in (5)(12), however, though perhaps there is a diachronic relationship. For one thing, the two forms are not actually homophonous. The $i$ - prefix in (5)-(12) generally is a more reduced form of the high front vowel, as evidenced by a frequently lowered second formant that reveals a more retracted position in the F1-F2 vowel space. Furthermore, a sampling of ten $i$ - prefixes and ten $i$ free pronouns revealed that the pronouns are generally $20-30 \mathrm{~ms}$ longer than the prefixes in question. The obvious motivation for the less reduced phonetic features of the $i$ pronoun is that it is not prefixal, and therefore is a monomorphemic word and receives word-level stress. The $i$ - prefix is never stressed since word-level stress is typically root final in $\mathrm{K}$. For a more complete discussion of stress and an acoustic analysis of $\mathrm{K}$ vowels, see Everett (to appear).

The other reason the previous treatment of the $i$ - form in negated transitive clauses does not work is that the form can grammatically occur in clauses without any $3^{\text {rd }}$ person referent, for example (16).

$$
\begin{array}{lll}
\text { in } \quad \text { i-mĩ: } & \text { padni } & \text { ãn } \\
\text { 1S NEG.TRANS-hit } & \text { NEG } & \text { 2S } \\
\text { 'I did not hit you.' } & &
\end{array}
$$

Storto (1999:121) echoes Landin's analysis, glossing the $i$ - prefix as ' 3 ', for instance in the following example:

$$
\begin{aligned}
& \text { taso i-oky-t } \quad \text { boroja } \\
& \text { man 3-kill-NFUT snake } \\
& \text { 'The man killed the snake.' (non-decl) }
\end{aligned}
$$

She notes that such a clause is a non-declarative clause, but does not note that it is actually a case of clausal negation. All K speakers I have presented with this clause note that it must be interpreted as meaning the man in question did not kill the snake.

It seems clear, then, that the $i$ - negational prefix cannot be interpreted as a $3^{\text {rd }}$ person pronoun. The similarity between this negational prefix and the $i$-prefix attached to semantically intransitive verbs has not been discussed in detail until

\footnotetext{
${ }^{4}$ The prefix glossed NSAP in (15) is employed when the absolutive referent of a clause is not a speech act participant, i.e. not a 1 st or $2^{\text {nd }}$ person referent.
} 
now. These two forms are in fact homophonous with each other, but not with the stressed $3^{\text {rd }}$ person pronoun. Furthermore, both prefixes occur in clauses (such as (5)-(8) and (16)) without any $3^{\text {rd }}$ person referents.

\subsection{Other Relevant Features of Clauses with Negated Transitives}

Word order in K is flexible (cf. Storto 1999, Everett 2006). However, in declarative clauses with intransitive verbal inflection, as well as in clauses with negated transitive verbs, the verb typically follows any overt ' $\mathrm{S}$ ' or ' $\mathrm{A}$ ' arguments. This is apparent in a number of the examples above. One way in which these two clause types do differ, however, is that a second nominal in a semantically intransitive clause must occur with an enclitic, frequently the $-t \dot{t}$ oblique marker. In negated transitive clauses with an overt second argument, no oblique marking is necessary. Consider first the following example of a declarative clause with an obliquemarked NP following the verb:

$$
\begin{array}{lll}
\text { in } & \text { i-diwit- } \varnothing & \text { manga-ti } \\
1 \mathrm{~S} & \text { INT-forget-NFUT } & \text { mango-OBL } \\
\text { 'I forgot the mango.' } &
\end{array}
$$

A semantically transitive verb cannot occur with this enclitic in an affirmative clause:

$$
\begin{aligned}
& \text { in } \quad \text { na-Pasika-t pikõmo }(*-t i) \\
& 1 S \text { NSAP-shoot-NFUT wooly monkey-OBL } \\
& \text { 'I shot the wooly monkey.' }
\end{aligned}
$$

This restriction also holds in negative clauses with transitive verbs:

$$
\begin{array}{ll}
\text { in } \quad \text { i-Pasika-t } & \text { pikõmo }(* \text {-ti) } \\
\text { 1S NEG.TRANS-shoot-NFUT } & \text { wooly monkey-OBL } \\
\text { 'I didn't shoot the monkey.' } &
\end{array}
$$

There is a clear structural similarity between intransitive clauses marked for valence and negated transitive clauses. While such clause types are not identical, i.e. they vary in terms of oblique marking, there is a clear similarity between them in terms of morphology and word order. This similarity is all the more notable considering that there are numerous ways in which declarative clauses with intransitive verbs differ from declarative clauses with transitive verbs in $\mathrm{K}$. The permissibility (or lack thereof) of $i$ - verbal prefixation is only one of many such 


\section{Caleb Everett}

structural reflections of the distinction. For the sake of space, I refer the reader to Everett (2006, part II) for a more detailed consideration of these reflections. ${ }^{5}$

\subsection{Data from Interrogatives and Imperatives}

Interestingly, semantically intransitive clauses such as those in the left-hand column of (1) are also similar to other clause types, namely transitive interrogatives and transitive imperatives. Not insignificantly, researchers such as Payne (1997:245) have noted that, "Interrogative and imperative clauses are likely to be irrealis, since they do not assert that X did happen, but order it to come about, or question whether it will or did come about." The correlation between irrealis and intransitivity has also been noted in the literature, for instance in Hopper and Thompson's (1980) work on scalar transitivity. ${ }^{6}$

The similarity between declarative clauses with semantically intransitive predicates and interrogative clauses with semantically transitive predicates is apparent in (21)-(22), two yes/no questions:

$$
\begin{array}{lll}
\text { ãn } \quad \text { i- } & \text { jgok-(o) } & (\mathrm{h} \tilde{\mathrm{t}}) \\
\text { 2S NEG.TRANS.Q-eat manioc-Q.NOM } & \mathrm{Q} \\
\text { 'Did you eat the manioc?' } &
\end{array}
$$
ãn i-mhip
hĩm-(o)
2S NEG.TRANS.Q-cook meat-Q.NOM Q
'Did you cook the animal meat?'

Note that these interrogatives do differ from the negated transitives considered above in that they may occur with a clause-final question particle. However, this particle, like the suffix attached to the $O$ noun in (21) and (22) is not required. What is required, however, is the $i$ - prefix attached to the verb. This prefixation characterizes predicates in content-word questions as well:

\footnotetext{
5 To cite just one example, declarative copular clauses can only occur with predicate nominals, predicate adjectives, and with participle-like semantically intransitive predicates, as in the following example.

$\begin{array}{lll}\text { i } & \text { na-aka-t } & \text { i-kisep- } \varnothing \\ 3 & \text { NSAP-COP-NFUT } & \text { INT-jump-COP.AGR } \\ \text { 'He's jumping.' } & \end{array}$

Crucially, such copular clauses cannot occur with semantically transitive predicates.

${ }^{6}$ These authors consider 'Mode', i.e. the realis-irrealis distinction, to be one of the ten defining features of scalar transitivity.
} 
Similarly, $i$ - prefixation is required for transitive verbs in imperative clauses. (24) contains a sample list of such imperatives with an optional $2^{\text {nd }}$ person singular pronoun. Note that consonant-final imperative verbs occur with an $-a$ suffix. Vowel-final imperative verbs, however, are only distinguishable morphologically by the presence of the $i$ - prefix. $^{7}$

\section{(24) Examples of transitive imperative verbs}

Transitive Im
(ãn) i-pidn-a
(ãn) i-mhiw-a
(ãn) i-m?a
(ãn) i-paka
(ãn) i-mĩ
(ãn) i-opĩ

$$
\begin{aligned}
& \text { Gloss } \\
& \text { 'kick (it)!' } \\
& \text { 'cook (it)!' } \\
& \text { 'make it!' } \\
& \text { 'clean (it)!' } \\
& \text { 'hit (it)!' } \\
& \text { 'cut (it)!' }
\end{aligned}
$$

This i- prefixation also occurs with hortatives, i.e. first-person imperatives such as the following:

$$
\begin{aligned}
& \text { i:t } \int \mathrm{i} a \text {-oki } \quad \text { (pikõm) } \\
& \text { 1PL } \\
& \text { 'Let's kill it.' or 'Let's kill the macaco prego/wooly monkey.' }
\end{aligned}
$$

Based on all the examples considered so far, as well as other similar examples in my data, it seems clear that there is a remarkable similarity between the form of declarative clauses with semantically intransitive verbs and the form of semantically transitive negative, interrogative, and imperative clauses. The motivation for this structural isomorphism is discussed in the following section.

\section{Untransitivity}

Faced with the data presented above, we are left to wonder what motivates the described structural similarity between the relevant clause types. Put another way, why is it that (26) is ambiguous, meaning either 'shoot it', 'you did not shoot it', or 'did you shoot it?'

$$
\begin{array}{ll}
\text { ãn } & \text { i-Pasika } \\
\text { 2S } & \text { i-shoot }
\end{array}
$$

\footnotetext{
${ }^{7}$ As Landin (1984) first noted, however, pitch is increased on the stressed syllable of imperative verbs.
} 


\section{Caleb Everett}

The desired interpretation is differentiated by prosody (for imperatives) as well as optional post-verbal morphemes (for negatives and interrogatives), nevertheless there is clearly a gross similarity across the structure of the relevant clause types.

Reflections of semantic transitivity or valency in the morphosyntax of a language are in some sense universal (cf. e.g. Dixon 1994). However the extent to which the semantically intransitive/transitive distinction surfaces in the structure of a language varies significantly cross-linguistically. In the case of Tupí languages, the distinction is usually readily apparent in the morphology. As Rodrigues notes, these languages "typically have one pronominal prefix to the verb indicating a core argument and may also have a prefix that marks change in valency" (1999:114). In the largest branch of the family, Tupí-Guaraní, languages generally distinguish between semantically transitive and semantically intransitive verb types (Jensen 1999:154).

While the accounts of semantic valency in the literature vary somewhat, it is generally agreed that such valency is primarily concerned with the number of participants that must be 'on stage' in the scene expressed by the verb (Payne 1997:169-170).

In the case of $\mathrm{K}$, the distinction surfacing is not one of simple semantic intransitivity/transitivity, since the number of participants that must be 'on stage' is clearly not defined on a lexico-semantic basis alone. When one considers data such as those in (1) alone, this approach to the factors involved works. However, when other data are considered, in particular those related to the negation of semantically transitive predicates, it becomes clear that the relevant distinction is not one of mere semantic valency. Instead, the crucial factor correlating with the distribution of the $i$ - prefix is the absence of an affected second participant (Otype argument) in a particular construction. That is, those constructions that preclude the existence of a real, already-affected second participant, be they intransitive declaratives or semantically transitive negatives, interrogatives, and imperatives, are tied together via the $i$ - prefix, which highlights a feature they all share. That feature is not simply one of lexico-semantic intransitivity, since all verb roots can be inflected with the $i$ - prefix, in accordance with utterancespecific factors. It is also not one of syntactic intransitivity, since in many cases the relevant clauses have two overt syntactic arguments. Instead, the shared feature might be termed untransitivity, the absence of an affected participant associated with a particular instance of the verb. ${ }^{8}$

Despite a significant amount of work on semantic valency over the last few decades, it is not always clear why distinctions such as that described above are so prevalent in languages. Prototypically transitive clauses are exceedingly rare in discourse (Thompson and Hopper 2001, Dahl 2000, Everett 2009). Nevertheless,

\footnotetext{
${ }^{8}$ The presence of an affected participant is one of the ten features of scalar transitivity noted by Hopper and Thompson (1980). For the K data, we see that this feature is the crucial feature distinguishing the two relevant categories, and for that reason I choose to adopt a new term. Also, the term is warranted by the fact that the semantically intransitive/transitive distinction more aptly applies to K declarative clauses, as seen in (1).
} 


\section{Negation and the Untransitive Category in Karitiâna}

events can clearly be divided quite productively according to semantic parameters such as presence or absence of an affected second argument. This distinction has been shown to be particularly relevant to the grammar of $\mathrm{K}$. The distinction in question has surfaced through the examination of a correlation between various clause types, particularly negatives, interrogatives, imperatives, and declaratives with semantically intransitive verbs. While similar correlations between such clause types have been observed for inter-linguistic data, $\mathrm{K}$ allows us to consider a particularly clear correlation in a set of intra-linguistic data. In the above analysis, this correlation began to crystallize most clearly via the examination of the negation of semantically transitive verbs, which proved essential to uncovering the putative category of untransitivity.

\section{References}

Dahl, Östen. 2000. Egophoricity in discourse and syntax. Functions of Language 7:1 37-77.

Dixon, R.M.W. 1994. Ergativity. Cambridge: Cambridge University Press.

Everett, Caleb. 2006. Patterns in Karitiâna grammar: Articulation, perception, and grammar. PhD diss., Rice University.

Everett, Caleb. 2008. Locus equation analysis as a tool for linguistic field work. Language Documentation and Conservation 2:185-211.

Everett, Caleb. 2009. A reconsideration of the motivations for Preferred Argument Structure. Studies in Language 33:1-24.

Everett, Caleb. To appear. Aspects of Karitiâna vowels. Anthropological Linguistics.

Hopper, Paul J., and Sandra A. Thompson. 1980. Transitivity in grammar and discourse. Language 56:251-299.

Jensen, Cheryl. Tupí-Guaraní. In R.M.W. Dixon and Alexandra Aikhenvald, eds., The Amazonian languages, 23-61. Cambridge: Cambridge University Press.

Landin, David. 1984. An outline of the syntactic structure of Karitiana sentences. In Robert Dooley, ed., Estudos sobre linguas Tupi do Brasil. Brasília: SIL.

Nichols, Johanna, David Peterson, and Jonathan Barnes. 2004. Transitivizing and detransitivizing languages. Linguistic Typology 8:149-211.

Payne, Thomas. 1997. Describing morphosyntax. Cambridge: Cambridge University Press.

Rodrigues, Aryon. 1999. Tupí. In R.M.W. Dixon and Alexandra Aikhenvald, eds., The Amazonian languages, 107-124. Cambridge: Cambridge University Press.

Storto, Luciana. 1999. Aspects of a Karitiana grammar. Ph.D. diss., Massachusetts Institute of Technology.

Thompson, Sandra A., and Paul J. Hopper. 2001. Transitivity, clause structure, and argument structure: Evidence from conversation. In Joan Bybee, ed., Frequency and the emergence of linguistic structure, 27-60. Philadelphia: John Benjamins. 


\section{Caleb Everett}

Van Valin, Robert D. 2005. Exploring the syntax-semantics interface. Cambridge: Cambridge University Press.

Caleb Everett

University of Miami

Department of Anthropology

P.O. Box 248106

Coral Gables, Florida 33124-2005

caleb@miami.edu 